\title{
Human Histocompatibility Leukocyte Antigen (HLA) Haplotype Frequencies Estimated from the Data on HLA Class I, II, and III Antigens in 111 Japanese Narcoleptics
}

Kazumasa Matsuki, Takeo Juji, Katsushi Tokunaga, Tohru Naohara, Masahiro Satake, and Yutaka Honda Blood Transfusion Service, Tokyo Women's Medical College Hospital, Tokyo, Japan; Blood Transfusion Service, Tokyo University Hospital, Tokyo, Japan; Department of Anthropology, Faculty of Science, Tokyo University, Tokyo, Japan; Department of Surgery, Faculty of Medicine, Tohoku University, Sendai, Japan; and Seiwa Hospital, Neuropsychiatric Research Foundation, Tokyo, Japan

\begin{abstract}
In order to deduce the predominant haplotypes in Japanese narcoleptics, we have studied a total of 111 Japanese patients with narcolepsy and six multiple-case families for HLA class I and class II antigens, and for class III HLA-linked complement markers. In Japanese narcoleptics, the most frequent haplotypes were B35-DR2, B15-DR2, and B51-DR2. These haplotypes were rare in normal Japanese population. In contrast, the most frequent haplotype of HLA-DR2 in normal Japanese, A24-C blankBw52-C4A*2 B*Q0-BF *S-C2*C-DR2-DQw1, had a decreased frequency to one-third of the normal controls. Haplotypes B35DR2, B15-DR2, and B51-DR2, which were more frequent among Japanese narcoleptics, were different from the haplotype found more frequently among Caucasoid narcoleptics, A3-Cw7-B7DR2-DQw1. Haplotype analysis on six families showed that B35-DR2 and other rare haplotypes in normal Japanese were associated with narcolepsy. There were four cases without any signs of narcolepsy among 19 subjects with the disease susceptibility haplotypes. This finding suggests an incomplete penetrance of hepersomnia. Haplotype analysis of family members was also useful for the early detection of the high risk children to narcolepsy.
\end{abstract}

\section{Introduction}

Narcolepsy is a sleep disorder characterized by recurrent napping in the daytime persisting for years (napping habit), irresistible attacks of sleep (sleep attacks), and sudden loss of tone in the striated muscles which typically occurs at moments of increased emotion (cataplexy). Other characteristics of narcolepsy are sleep paralysis, which is often accompanied by vivid and frightening hallucinations, and a rapid eye movement period at the onset of sleep.

The precise etiology of narcolepsy is unknown. It appears certain, however, that genetic factors play a role in the pathogenesis of the disease (1-3). But only a few studies have been carried out regarding the relationship of various genetic markers and narcolepsy $(4,5)$.

Regarding the research on this relationship, we were the first to describe a strong association between HLA-DR2 and narcolepsy (6-8). HLA-DR2 was found positive in $100 \%$ of more than 40 Japanese narcoleptic patients $(6-8)$, and in $\sim 65 \%$ of

Received for publication 20 May 1985.

J. Clin. Invest.

(C) The American Society for Clinical Investigation, Inc. 0021-9738/85/12/2078/06 \$1.00

Volume 76, December 1985, 2078-2083 patients with excessive daytime sleepiness $(6,7)$. We also observed a significant increase in frequency of HLA-B35 and a significant decrease in frequency of Bw52 and B7 (5-8). A preliminary study on families with a narcolepsy proband showed a close association between HLA-DR2 and the disease (7). After our studies, other investigators reported that all the 37 English (9) and eight French (10) patients with narcolepsy were HLADR2 positive. These reports confirmed that a strong association between HLA-DR2 and the disease was also present in the Caucasoid population.

On the other hand, differences in HLA class I allele frequencies were observed between Japanese and Caucasoid patients. The frequency of HLA-B7 increased in Caucasoid patients $(9,11)$ while it decreased in Japanese patients (5-8). HLA-A2 increased in Japanese patients $(8,12)$ while HLA-A3 increased in Caucasoid narcoleptics (9). These data indicated that different haplotypes might be associated with narcolepsy in Japanese and Caucasoid patients.

In the present report, we extended the number of patients to 111 , and analyzed haplotype and gene frequencies statistically. HLA-linked complement markers were determined for the first time for narcoleptic patients. Family studies were also performed on six multiple-case families. Frequent haplotypes in Japanese narcoleptics were considered to be different from the frequent haplotypes found in Caucasoid patients and those commonly found in the normal Japanese.

\section{Methods}

111 outpatients with narcolepsy at the Department of Neuropsychiatry, Tokyo University Hospital (64 males and 47 females, between 16 and $74 \mathrm{yr}$ of age), and 308 apparently healthy Japanese were studied. All the cases with narcolepsy that had been typed for HLA antigens between March 1983 and December 1984 were included in this study. Previously reported cases $(5-8,12)$ were also included. Complement allotypes were determined for the patients who had been tissue-typed between October 1983 and July 1984.

Our diagnostic criteria of narcolepsy are as follows: (a) recurrent daytime naps, occurring almost every day and persisting for at least six months; $(b)$ clinical confirmation of cataplexy in the patient's history, concurrent with $a$. Both $a$ and $b$ must be present. Our criteria of narcolepsy' ${ }^{1}$ has been discussed elsewhere (1).

Serological HLA typing was performed by a standard microcytotoxity

1. In this paper, the terms "essential hypersomnia" and "excessive daytime somnolence" were also used. Essential hypersomnia is defined by the following criteria: (a) recurrent daytime naps, occurring almost every day and persisting for at least $6 \mathrm{mo}$; $(b)$ absence of cataplexy; (c) not due to other known disorders associated with daytime somnolence, such as sleep-apnea syndrome. Excessive daytime sleepiness is used to denote morbid somnolence with and without episodes of cataplexy on the basis of information obtained from family members. 
Table I. Antisera Used to Type DR2 and DQw1 in This Study

\begin{tabular}{lllll}
\hline Specificity & Name & Source & $r$ & Score 8 \\
\hline \multirow{4}{*}{ DR2 } & & & & $\%$ \\
& HU30* & Mouse monoclonal & 0.975 & 90.8 \\
& T874 & Postpartum blood & 0.944 & 82.4 \\
& AH5* & Postpartum blood & 0.899 & 97.8 \\
& T1193 & Postpartum blood & 0.873 & 71.0 \\
DQw1 & T397 & Postpartum blood & 0.907 & 74.9 \\
& T847 & Postpartum blood & 0.858 & 83.4 \\
& T424 & Postpartum blood & 0.812 & 78.0 \\
& & & & \\
\hline
\end{tabular}

* HU30 and AH5 were kind gifts from Dr. Aizawa at Hokkaido University and Dr. Yoshida at Hamamatsu Medical College, respectively. Others were obtained at Blood Transfusion Service, Tokyo Women's Medical College Hospital.

method using local and exchanged antisera. The antisera used to type for HLA-DR2 and DQw1 are listed in Table I. C2 and BF phenotypes were identified by the methods described previously $(13,14)$. C4 phenotypes were determined according to the method of Mauff et al. (15). Estimates of HLA class I and class II gene frequencies and their standard errors were obtained by a gene counting method of maximum likelihood (16). Haplotype frequencies and standard errors in the patient population were computed using the formulae given by Mittal et al. (17) and Piazza (18). Haplotype frequencies in the normal control subjects were obtained by direct counting from the family study data at the Eighth Japan HLA

Table II. Phenotype and Estimated Gene Frequencies of HLA Antigens in the Narcoleptic Patients and the Normal Subjects

\begin{tabular}{|c|c|c|c|c|c|c|c|}
\hline & \multicolumn{3}{|c|}{ Narcolepsy $(n=111)$} & \multicolumn{3}{|c|}{ Controls $(n=308)$} & \multirow{2}{*}{$\begin{array}{l}\text { Chi-square } \\
\text { values }\end{array}$} \\
\hline & PF & GF & SE & PF & GF & SE & \\
\hline A2 & 55.9 & 32.4 & 1.1 & 40.6 & 22.9 & 0.9 & 7.7 \\
\hline A3 & 0.0 & 0.0 & 0.0 & 1.6 & 0.8 & 0.2 & \\
\hline B7 & 1.8 & 0.9 & 0.6 & 11.0 & 5.7 & 0.4 & 7.7 \\
\hline B15 & 27.0 & 14.7 & 1.3 & 21.1 & 11.2 & 1.2 & \\
\hline B35 & 38.7 & 21.0 & 1.3 & 17.9 & 9.4 & 1.1 & 19.9 \\
\hline B51 & 26.1 & 13.8 & 1.3 & 16.6 & 8.7 & 1.1 & \\
\hline Bw52 & 7.2 & 3.8 & 1.0 & 22.4 & 11.9 & 1.2 & 12.6 \\
\hline Bw67 & 9.9 & 5.1 & 1.1 & 1.6 & 0.8 & 0.3 & 13.1 \\
\hline Cw3 & 64.0 & 39.9 & 3.5 & 46.1 & 26.6 & 1.9 & 10.4 \\
\hline Cw7 & 24.3 & 12.9 & 2.2 & 19.2 & 10.1 & 1.2 & \\
\hline DR1 & 2.7 & 1.4 & 0.7 & 14.6 & 7.6 & 0.9 & 10.2 \\
\hline DR2 & 100.0 & 60.5 & 1.0 & 33.8 & 18.6 & 1.0 & 141.0 \\
\hline DRw8 & 8.1 & 4.1 & 1.0 & 26.6 & 14.3 & 1.1 & 16.5 \\
\hline DRw9 & 10.8 & 5.4 & 1.0 & 27.6 & 14.9 & 1.1 & 12.9 \\
\hline DRw13 & 3.6 & 1.8 & 0.8 & 16.6 & 8.7 & 1.0 & 10.9 \\
\hline DRw52 & 30.9 & 17.2 & 2.6 & 57.1 & 34.5 & 2.2 & 24.1 \\
\hline DRw53 & 41.8 & 24.2 & 3.0 & 61.7 & 38.1 & 2.2 & 13.6 \\
\hline DQw1 & 100.0 & 77.4 & 4.8 & 59.7 & 36.5 & 2.2 & 61.6 \\
\hline
\end{tabular}

PF, phenotype frequencies (\%); GF, estimated gene frequencies (\%); $\mathrm{SE}$, standard errors of gene frequencies (\%). Chi-square values below 5 are not given in the table.
Workshop (19). Data in our previous reports were used as complement $\mathrm{C} 2$ and BF controls $(13,14)$. Chi-square test or Fisher's exact test was used to determine the statistical significance of comparative phenotype frequencies. Differences in haplotype frequencies were tested as described by Cavalli-Sforza and Bodmer (20).

\section{Results}

Phenotype and gene frequencies of HLA class I and class II antigens in 111 Japanese patients with narcolepsy. The phenotype and the estimated gene frequencies of HLA alleles are shown in Table II. All of the 111 patients with narcolepsy were HLA-DR2 positive (significantly increased in frequency at corrected $P$ $<10^{-29}$ ). The relative risk for DR2 was 436. The numbers of HLA-DR2 homozygotes and heterozygotes were 29 and 82, respectively. The phenotype frequency of DQw1 was also $100 \%$ in the narcoleptics (corrected $P<10^{-12}$ ). The frequencies of other DR alleles, DR1, DRw8, DRw9, and DRw13, were significantly decreased. The frequencies of "supertypic" antigens, DRw52 and DRw53, which do not usually associate with DR2, were also significantly decreased.

As for class I alleles, the frequencies of B35 and Bw67 were significantly increased in the patient group. The frequency of Bw52 decreased to about a third of that in the normal controls. The frequency of $B 7$ also decreased significantly. A significant increase in $\mathrm{A} 2$ and $\mathrm{Cw} 3$ frequencies was also observed.

HLA-linked complement markers. The frequency of $\mathrm{C} 2 * \mathrm{C}$ decreased and that of $\mathrm{C}^{*} \mathrm{AT}$ increased in the narcoleptic patients (Table III). The increase in $B F^{*} \mathrm{~F}$ frequency and the decrease

Table III. Complement Allele Frequencies in the Japanese Narcoleptic Patients

\begin{tabular}{|c|c|c|c|}
\hline Alleles & Narcolepsy & Controls & $P$ \\
\hline & $(n=46)$ & $(n=521)$ & \\
\hline C2 C & 87.8 & 93.9 & $<0.05$ \\
\hline AT & 8.9 & 3.4 & $<0.01$ \\
\hline B & 2.2 & 2.2 & \\
\hline \multirow{2}{*}{$\mathrm{BH}$} & 1.1 & 0.6 & \\
\hline & $(n=45)$ & $(n=487)$ & \\
\hline BF S & 62.0 & 80.1 & $<0.0001$ \\
\hline F & 38.0 & 19.8 & $<0.0001$ \\
\hline \multirow[t]{2}{*}{ FT } & 0.0 & 0.1 & \\
\hline & $(n=44)$ & $(n=169)$ & \\
\hline$C 4 A^{*} 3$ & 68.2 & 68.3 & \\
\hline$A^{*} 4$ & 17.0 & 13.6 & \\
\hline$A^{*} 2$ & 4.5 & 10.7 & $<0.05$ \\
\hline $\mathrm{A}^{*} \mathrm{QO}$ & 4.5 & 6.5 & \\
\hline A rares & 5.7 & 0.9 & $<0.01$ \\
\hline $\mathrm{B}^{*} 1$ & 51.1 & 58.0 & \\
\hline $\mathrm{B}^{*} 2$ & 26.1 & 17.2 & $<0.05$ \\
\hline$B^{* 5}$ & 6.8 & 8.9 & \\
\hline $\mathrm{B}^{*} \mathrm{QO}$ & 14.8 & 16.0 & \\
\hline$B$ rares & 1.1 & 0.0 & \\
\hline
\end{tabular}

Gene frequencies are given as percent. 
Table IV. C4 Haplotype Frequencies in Patients With Narcolepsy and Normal Subjects

\begin{tabular}{|c|c|c|c|c|c|}
\hline \multirow[b]{2}{*}{ Haplotypes } & \multicolumn{2}{|c|}{$\begin{array}{l}\text { Narcolepsy } \\
(n=43)\end{array}$} & \multicolumn{2}{|c|}{$\begin{array}{l}\text { Controls } \\
(n=169)\end{array}$} & \multirow[b]{2}{*}{$P$} \\
\hline & $\mathrm{HF}$ & SE & HF & SE & \\
\hline$A * 3 \quad B * 1$ & 46.3 & 8.6 & 53.0 & 2.7 & \\
\hline$A^{*} 4 B^{* 2}$ & 15.3 & 4.2 & 12.0 & 1.8 & \\
\hline$A^{*} 3 B^{*} 2$ & 13.1 & 9.5 & 3.9 & 1.1 & \\
\hline$A * 3 \quad B * 5$ & 6.1 & 2.7 & 5.7 & 1.3 & \\
\hline$A^{*} 4 B^{*} 1$ & 5.9 & 6.7 & 1.5 & 0.7 & \\
\hline$A^{*} 2 B^{*} Q O$ & 3.6 & 2.1 & 10.8 & 1.7 & $<0.005$ \\
\hline $\mathrm{A}^{*} \mathrm{QO} \quad \mathrm{B}^{*} 1$ & 1.1 & 3.2 & 6.0 & 1.3 & \\
\hline
\end{tabular}

$\mathrm{HF}$, estimated haplotype frequencies (\%); SE, standard errors (\%).

in $B F^{*} S$ frequency were significant. The frequency of $C 4 A^{*} 2$ decreased, while that of $C 4 B^{*} 2$ and $C 4 A$ rare alleles increased. The estimated frequency of $\mathrm{C}_{4} \mathrm{~A}^{*} 2 \mathrm{~B} * \mathrm{Q} 0$ was nearly one-third of the normal value $(P<0.005$, Table IV).

Estimated frequencies of two- and three-locus haplotypes. Table $\mathrm{V}$ gives the estimated frequencies and the standard errors of frequent two-locus haplotypes among the narcoleptic patients and those of the corresponding haplotypes in the normal subjects. Three haplotypes, B35-DR2, B15-DR2, and B51-DR2, which are rare in the Japanese $(19,21)$, were significantly increased in frequency among the narcoleptic patients. On the other hand, Bw52-DR2, which is one of the most frequent haplotypes among normal Japanese, decreased in frequency to about one-third of the normal controls in the narcoleptics $(0.1<P<0.2)$.

Table VI shows the frequent three-locus haplotypes in the Japanese narcoleptic patients. Haplotype A2-B35-DR2 was the most frequent, while haplotype A24-Bw52-DR2 decreased in frequency to about one-third of the controls.

HLA haplotype in six multiple-case families. Figs. 1 and 2 depict six multiple-case families and their deduced haplotypes. In family NS, all the family members with narcolepsy or excessive daytime sleepiness had the "a" haplotype, A31-Cw3-B35-C4A*4 $B^{*} 2-C 2 * C-B F{ }^{*} F-D R 2-D Q w 1$. In family SK, the "a" haplotype, A24-C blank-Bw52-C4A*13J B*Q0-C2*C-BF *S-DR2-DQw1, was associated with narcolepsy where $\mathrm{C} 4 \mathrm{~A} 13 \mathrm{~J}$ is a tentative

Table V. Two-locus Haplotype Frequencies in Narcoleptic Patients and Normal Subjects

\begin{tabular}{lrlllll}
\hline & \multicolumn{3}{l}{$\begin{array}{l}\text { Narcolepsy } \\
(n=111)\end{array}$} & & \multicolumn{2}{l}{$\begin{array}{l}\text { Controls } \\
(n=414)\end{array}$} \\
\cline { 2 - 3 } Haplotypes & HF & SE & & HF & SE & $P$ \\
\hline B35-DR2 & 217 & 73 & & 11 & 2 & $<0.005$ \\
B15-DR2 & 146 & 72 & & 16 & 3 & $<0.05$ \\
B51-DR2 & 141 & 71 & 9 & 2 & $<0.05$ \\
Bw61-DR2 & 85 & 70 & & 6 & 2 & \\
Bw54-DR2 & 65 & 69 & & 3 & 2 & \\
Bw52-DR2 & 37 & 68 & & 110 & 7 & $0.1<P<0.2$
\end{tabular}

HF, estimated haplotype frequencies (per 1,000); SE, standard errors (per 1,000).
Table VI. Three-locus Haplotype Frequencies in Narcoleptic Patients and Normal Subjects

\begin{tabular}{lll}
\hline Haplotypes & $\begin{array}{l}\text { Narcolepsy }(n=111) \\
\text { HF }\end{array}$ & $\begin{array}{l}\text { Controls }(n=414) \\
\text { HF }\end{array}$ \\
\hline A2-B35-DR2 & 814 & 35 \\
A24-B35-DR2 & 560 & 36 \\
A24-B51-DR2 & 544 & 23 \\
A2-B51-DR2 & 534 & 22 \\
A2-B15-DR2 & 508 & 37 \\
A24-Bw52-DR2 & 305 & 918 \\
& & \\
\hline
\end{tabular}

HF, estimated haplotype frequencies (per 10,000).

designation of a rare $\mathrm{C} 4 \mathrm{~A}$ variant which migrates electrophoretically near C4A 13 . Two children of the proband (III 2 and III 3) who had the same "a" haplotype did not show any signs of narcolepsy. In family YM, the "a" haplotype, A2-Cw3-B35DR2-DQw1, was considered to be a susceptibility haplotype.

In family AK, two family members with the "a" haplotype, A2-Cw1-Bw54-DR2-DQw1, had narcolepsy. The second child of the proband (III 6,15 yr old) had the "a" haplotype. In his case, he had not been seriously aware of his somnolence before being interviewed for this study. He used to nap in the classroom over the past year, could not concentrate on studying, and his grades recently dropped. He attributed this to his devotion to baseball practice. In his case, no cataplexy, hypnagogic hallucinations, or sleep paralysis were confirmed. A polysomnogram of this patient showed a rapid eye movement period within 10

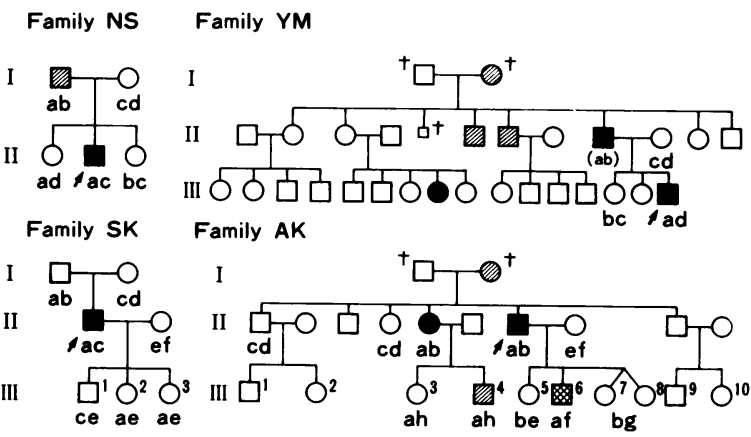

Figure 1. Pedigrees of four families with narcoleptic patients. Arrows indicate probands: $\square$, normal; $\square$, narcolepsy; $\square$, essential hypersomnia; b, excessive daytime sleepiness; $\dagger$, deceased. In family NS, $a, \mathrm{~A} 31$ Cw3-B35-C4A*4 B*2-BF *F-C2*C-DR2-DQw1; $b$, A24-Cw7-B7$\mathrm{C}^{*} \mathrm{~A}^{*} 3 \mathrm{~B}^{*} 1-\mathrm{BF} * \mathrm{~S}-\mathrm{C} 2{ }^{*} \mathrm{C}-\mathrm{DR} 1-\mathrm{DQw1} ; c$, A24-C blank-Bw52-C4A*3 $\mathrm{B}^{*} 1-\mathrm{BF}{ }^{*} \mathrm{~F}-\mathrm{C} 2{ }^{*} \mathrm{C}-\mathrm{DR} 2-\mathrm{DQw} 1 ; d, \mathrm{~A} 24-\mathrm{Cw} 3-\mathrm{Bw} 60-\mathrm{C} 4 \mathrm{~A}^{*} 4 \mathrm{~B}^{*} 2-\mathrm{BF}{ }^{*} \mathrm{~S}-$ $\mathrm{C} 2{ }^{*} \mathrm{C}-\mathrm{DR} w 6-\mathrm{DQw} 3$. In family YM, $a, \mathrm{~A} 2-\mathrm{B} 35-\mathrm{Cw} 3-\mathrm{DR} 2-\mathrm{DQw} 1 ; b$, A11-Bw39-Cw7-DR2-DQw1; $c$, A2-Bw54-Cw1-DR2-DQw1; d, A11Bw55-Cw1-DR8-DQw1. In family SK, $a$, A24-C blank-Bw52$\mathrm{C}_{4} \mathrm{~A}^{* 1}$ 3J B*Q0-BF *S-C2*C-DR2-DQw1; $b, \mathrm{~A} 24-\mathrm{Cw} 7-\mathrm{B} 7-\mathrm{C} 4 \mathrm{~A}^{*} 3$ $\mathrm{B}^{*} 1-\mathrm{BF}{ }^{*} \mathrm{~S}-\mathrm{C} 2{ }^{*} \mathrm{C}-\mathrm{DR} 1-\mathrm{DQw} 1 ; c, \mathrm{~A} 2-\mathrm{Cw} 3-\mathrm{B} 35-\mathrm{C} 4 \mathrm{~A}^{*} 3 \mathrm{~B}^{*} 1-\mathrm{BF}{ }^{*} \mathrm{~F}-$ C2*C-DR2-DQw1; $d$, A33-C blank-Bw61-C4A*3 B*1-BF*S-C2*C$\mathrm{DRw} 1$ 1-DQw3; $e$, A2-Cw3-B35-C4A*3 B*2-BF*S-C2*C-DR4-DQw3; $f$, A2-C blank-B39-C4A*4 $\mathrm{B}^{*} \mathrm{Q} 0-\mathrm{BF} * \mathrm{~S}-\mathrm{C} 2{ }^{*} \mathrm{C}-\mathrm{DR} 2-\mathrm{DQw} 1$. In family $\mathrm{AK}, a$, A2-Cw1-Bw54-DR2-DQw1; $b$, A2-Cw1-Bw54-DR4-DQ blank; c, A31-Cw3-Bw61-DRw12-DQw3; d, A24-C blank-Bw52-DR2-DQw1; $e, \mathrm{~A} 11-\mathrm{Cw} 4-\mathrm{B} 15-\mathrm{DR} 4-\mathrm{DQw} 3 ; f, \mathrm{~A} 2-\mathrm{CX} 46-\mathrm{Bw} 46-\mathrm{DR} 8-\mathrm{DQw} 1 ; g, \mathrm{~A} 11$ Cw4-B15-DR8-DQw1; $h$, A 11-Cw3-B35-DR2-DQw1. 


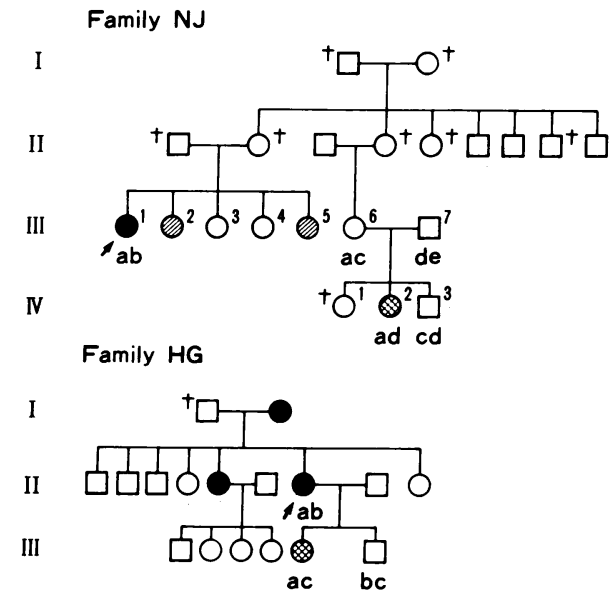

Figure 2. Pedigrees of two families. In family NJ, $a, \mathrm{~A} 26-\mathrm{Cw} 3-\mathrm{B} 35-$ DR2-DQw1; $b$, A1-C blank-B37-DR2-DQw1; $c$, A2-Cw3-Bw60$\mathrm{DRw} 9-\mathrm{DQw} 3 ; d, \mathrm{~A} 2-\mathrm{CX} 46-\mathrm{Bw} 46-\mathrm{DRw} 8-\mathrm{DQw} 1 ; e, \mathrm{~A} 31-\mathrm{C}$ blank-B51DRw12-DQw3. In family HG, $a$, Al1-Cw7-Bw67-DR2-DQw1; $b$, A33-C blank-B44-DRw13-DQw1; $c$, A24-Cw1-Bw59-DRw12-DQw3. See Fig. 1 for explanation of symbols.

min from the onset of sleep, and a marked tendency to fall asleep. He is now under medication with pemoline, and is successfully attending college without daytime somnolence. In this family, four family members with the "a" haplotype had excessive somnolence, while the first child (III 3) of the proband's sister with the "a" haplotype did not show any signs of narcolepsy.

In family NJ, the proband (III 1) and her relative (IV 2) had the same "a" haplotype, A26-Cw3-B35-DR2-DQw1. In this case, the mother (III 6) of the relative also had the " $a$ " haplotype, but did not show any signs of excessive somnolence. In family $\mathrm{HG}$, the "a" haplotype, A11-Cw7-Bw67-DR2-DQw1, was associated with narcolepsy and essential hypersomnia. In these families, three out of six "a" haplotypes associated with narcolepsy were B35-Cw3-DR2-DQw1.

\section{Discussion}

The present study shows that certain rare haplotypes increased statistically among Japanese narcoleptic patients. These rare haplotypes with increased frequency were B35-DR2, B15-DR2, and B51-DR2. Also, three-locus haplotypes, A2-B35-DR2, A24B35-DR2, A24-B51-DR2, A2-B51-DR2, and A2-B15-DR2 had increased in frequency. These haplotypes were uncommon among the healthy Japanese population $(19,21)$.

On the other hand, the frequencies of HLA-Bw52, Bw52DR2, A24-Bw52-DR2, and a complement C4 haplotype A*2 $B^{*} Q 0$ had decreased to about one-third of the frequency in normal Japanese. These data indicate a decrease in the narcoleptics of the most common haplotype of HLA-DR2 found in normal Japanese, A24-C blank-Bw52-C4A*2 B*Q0-BF *S-C2*C-Dw12DR2-DQw1 $(19,21)$. The decrease of $C 2 * C$ and $B F^{*} S$ frequencies was less evident because they are also linked with other haplotypes (22).

Similar differential changes in haplotype frequencies were observed in ankylosing spondylitis. Terasaki and Mickey (23) computed haplotype frequencies from the data of patients with ankylosing spondylitis, and found that the frequencies of A1B27 and A3-B27 were lower, while that of A30-B27 was higher than expected from the controls. If HLA-B27 itself were a disease susceptibility gene, haplotype frequencies of HLA-B27 should have raised equally. They speculated that a disease susceptibility gene to ankylosing spondylitis was not HLA-B27 itself but a gene(s) other than HLA-B27, linked to the "diseased" haplotype.

In narcolepsy the situation is more complicated, since HLADR2 may split into more than one specificity (24). Increased haplotypes in narcolepsy may bear a split antigen(s) of HLADR2 different from that of the common haplotypes, and that split antigen(s) may associate with narcolepsy. Similarly, possible split antigens of HLA-DQw1 have been proposed $(25,26)$. We must first consider possible differences between the rare increased haplotypes and the common decreased haplotype.

One possibility is that HLA-D alleles were different between these haplotypes. HLA-D specificity in strong linkage disequilibrium with haplotype A24-C blank-Bw52-DR2, the most common haplotype in the normal Japanese, is HLA-Dw12 (27). Since the frequency of haplotype had significantly decreased, we can assume that HLA-Dw12 possibly decreased. Several other cytologically determined specificities have been known to associate with HLA-DR2, including Dw2, FJ0, DB9, and MN2 (24). Except for the haplotype HLA A24-C blank-Bw52-DR2 and HLA-Dw12, no data has been available as to which haplotype associates with which HLA-D specificity in the Japanese. The rare haplotypes may carry HLA-Dw2, as would be the case in Caucasoid patients, but this should be substantiated.

Another possibility is that DQ alleles are different. Recent studies have shown that DQ genes have a higher level of polymorphism than is currently recognized by serological methods $(28,29)$. Restriction fragment length polymorphism has been demonstrated within the same DQw1 and DR2 specificities (28, $29)$. Since DQw1 has also been found $100 \%$ positive in narcoleptics, a primary disease susceptibility factor could be DQ allele.

It is also possible that there is no difference in HLA-DR or DQ alleles for the rare and common haplotypes. If there is no difference, the presence of a disease susceptibility gene(s) itself on the rare haplotypes would be the only distinguishing feature. Further studies are needed to clarify the key differences between the rare and common haplotypes.

Among Caucasoid narcoleptics, A3, B7, Cw7, DR2, and DQw 1 had increased in frequency (9-11). A3-Cw7-B7-DR2DQwl is one of the most frequent haplotypes among Caucasoids, and it usually associates with HLA-Dw2. In our research on Japanese narcoleptics, there was no evidence to indicate an increase of this haplotype. This ethnic difference in haplotype frequencies seems to be the cause of the difference in HLA class I antigen frequencies between Japanese and Caucasoid narcoleptic patients.

Our results show that only heterozygous expression of HLADR2 was sufficient for the development of narcolepsy. The ratio of HLA-DR2 homozygotes to heterozygotes is explained by assuming a dominant inheritance model of a putative disease susceptibility gene linked to HLA-DR2 (Table VII). A recessive model can be ruled out at $P<10^{-28}$ (chi square $=126$ ). This dominant inheritance model regarding HLA-DR2 was also reported to be applicable in cases of Caucasoid narcolepsy (9).

Our study on six multiple-case families shows that all the patients with somnolent disorders were HLA-DR2 positive, and family members who were HLA-DR2 negative never developed 
Table VII. Observed and Expected Phenotype Frequencies in Patients With Narcolepsy

\begin{tabular}{|c|c|c|c|}
\hline \multirow[b]{2}{*}{ Phenotype } & \multirow{2}{*}{$\begin{array}{l}\text { Observed } \\
\text { no. }\end{array}$} & \multicolumn{2}{|c|}{ Expected no. } \\
\hline & & Dominant & Recessive \\
\hline DR2/DR-* & 29 & 22.31 & 111 \\
\hline DR2/DRx & 82 & 88.69 & 0 \\
\hline DRx/DRx & 0 & 0 & 0 \\
\hline Chi-square value & & 1.13 & 126 \\
\hline$P$ & & 0.29 & $<10^{-28}$ \\
\hline
\end{tabular}

* DR2-DR- = DR2/DR2, DR2/DR blank; DRx = DR alleles other than DR2; DRx/DRx = DRx/DRx, DRx/DR blank, DR blank/DR blank.

narcolepsy. The most frequent haplotype that was associated with narcolepsy was B35-Cw3-DR2-DQw1 in this family study. This was in good agreement with the computation from the population data, in which B35-DR2 was most frequent. No family showed the association with the most frequent haplotype in normal Japanese, A24-C blank-Bw52-C4A*2 B*Q0-BF *S$\mathrm{C} 2{ }^{*} \mathrm{C}-\mathrm{Dw} 12-\mathrm{DR} 2$. These results, along with the population data, suggest that rare haplotypes are associated with narcolepsy, and that the common haplotype is not.

Four family members (III 2 and III 3 in family SK, III 3 in family AK, and III 6 in family NJ) who had the disease susceptibility haplotype did not show any signs or symptoms of narcolepsy. In the six families studied, 19 subjects had disease susceptibility haplotypes. Among them, eight subjects were suffering from narcolepsy, three from essential hypersomnia, four from excessive daytime sleepiness, and four had no symptoms of excessive daytime somnolence. This data shows that there were subjects who did not develop narcolepsy even if they had a disease susceptibility HLA haplotype. This incomplete penetrance of the disease and the multiform appearance of both narcolepsy and essential hypersomnia suggest that factors other than a HLADR2-linked disease susceptibility gene(s) are also required for the full manifestation of narcolepsy. This finding agrees with a two-threshold multifactorial inheritance model previously proposed by many investigators $(1,3)$. In some cases, environmental factors seem to play a precipitating role in the development of narcolepsy.

In family AK, haplotype analysis was useful to detect a family member at risk of narcolepsy. A subject without HLA-DR2 seems completely free from narcolepsy, but a subject with HLADR2 has a certain possibility to develop it $(5,6)$. Haplotype analysis of the family members is useful for the early detection of the high risk children to narcolepsy, and also for the possible prevention of the development of narcolepsy by avoiding precipitating environmental factors that may contribute to the development of the disease.

\section{Acknowledgments}

We are thankful to all the narcoleptic patients who were willing to participate in our studies. We also thank Ms. H. Yoshida and Mr. S. Takahashi for expert technical assistance, and Ms. T. Abbott for help in preparing the manuscript.

\section{References}

1. Honda, Y., A. Asaka, M. Tanimura, and T. Furusho. 1983. A genetic study of narcolepsy and excessive daytime sleepiness in $308 \mathrm{fam}$ ilies with a narcolepsy or hypersomnia proband. In Sleep/Wake Disorders. C. Guilleminault and E. Lugaresi, editors. Raven Press, New York. 187199.

2. Bruhova, S., and B. Roth. 1972. Heredofamilial aspects of narcolepsy and hypersomnia. Arch. Suisses Neurol. Neurochir. Psychiatr. 110:45-54.

3. Kessler, S., C. Guilleminault, and W. C. Dement. 1974. A family study of 50 REM narcoleptics. Acta. Neurol. Scand. 50:503-512.

4. Asaka, A., K. Park, Y. Honda, G. Kuroiwa, S. Tsuji, H. Hamaguchi, M. Akizuki, M. Matsumoto, and K. Omoto. 1981. A study on genetic markers in intractable diseases. In 1980 Annual Report of Research Committee on Host Factors of Intractable Diseases. I. Watanabe, editor. Ministry of Health and Welfare, Tokyo. 123-131.

5. Honda, Y., A. Asaka, Y. Tanaka, and T. Juji. 1983. Discrimination of narcoleptic patients by using genetic markers and HLA. Sleep Research. 12:254.

6. Honda, Y., Y. Doi, T. Juji, and M. Satake. 1984. Narcolepsy and HLA: positive DR2 as a prerequisite for the development of narcolepsy. Folia. Psychiatr. Neurol. Jpn. 38:360.

7. Honda, Y., Y. Doi, T. Juji, and M. Satake. 1984. Positive HLADR2 finding as a prerequisite for the development of narcolepsy. In Proceedings of the 9th meeting of Japanese Society of Sleep Research May $11,1984.8$.

8. Juji, T., M. Satake, Y. Honda, and Y. Doi. 1984. HLA antigens in Japanese patients with narcolepsy. All the patients were DR2 positive. Tissue Antigens. 24:316-319.

9. Langdon, N., K. I. Welsh, M. V. Dam, R. W. Vaughan, and D. Parkes. 1984. Genetic markers in narcolepsy. Lancet. II:1178-1180.

10. Billiard, M., and J. Seignalet. 1985. Extraordinary association between HLA-DR2 and narcolepsy. Lancet. I:226-227.

11. Seignalet, J., and M. Billiard. 1984. Possible association between HLA-B7 and narcolepsy. Tisssue Antigens. 23:188-189.

12. Juji, T., K. Matsuki, T. Naohara, M. Satake, and Y. Honda. 1985. Lancet. I:227.

13. Tokunaga, K., C. Araki, T. Juji, and K. Omoto. 1982. Polymorphism of properdin factor $B$ in Japanese: description of a rare variant and data of association with HLA and C2. Hum. Genet. 60:42-45.

14. Tokunaga, K., C. Araki, T. Juji, and K. Omoto. 1981. Genetic polymorphism of the complement $\mathrm{C} 2$ in Japanese. Hum. Genet. 58: 213-216.

15. Mauff, G., C. A. Alper, Z. Awdeh, J. R. Batchelor, J. Bertrams, G. Bruun-Petersen, R. L. Dawkins, P. Demant, J. Edwards, H. GrosseWilde, G. Hauptmann, P. Klouda, L. Lamm, E. Molenhauser, M. H. Roos, V. Skanes, P. Teisberg, and L. Wells. 1983. Statement on the nomenclature of human C4 allotypes. Immunobiology. 164:184-191.

16. Yasuda, N., and K. Tsuji. 1975. A counting method of maximum likelihood for estimating haplotype frequency in the HL-A system. Jpn. J. Hum. Genet. 20:1-15.

17. Mittal, K. K., T. Hasegawa, A. Ting, M. R. Mickey, and P. I. Terasaki. 1972. Genetic variation in the HL-A system between Ainus, Japanese, and Caucasians. In Histocompatibility Testing 1972. P. I. Terasaki, editor. Munksgaard, Copenhagen. 187-195.

18. Piazza, A. 1975. Haplotypes and linkage disequilibria from the three-locus phenotype. In Histocompatibility Testing 1975. F. KissmeyerNielsen, editor. Munksgaard, Copenhagen, 923-927.

19. Fujii, T., T. Juji, and N. Kaihara. 1983. Family Study of HLAA, B, C, and DR in Japanese. Ishoku. 18:189-203.

20. Cavalli-Sforza, L. L., and W. F. Bodmer. 1970. Statistics and Probability. In The Genetics of Human Populations. L. L. Cavalli-Sforza and W. F. Bodmer, editors. W. H. Freeman and Co., San Francisco. 822.

21. Baur, M. P., M. Neugebauer, and E. D. Albert. 1984. Reference table of two-locus haplotype frequencies for all MHC marker loci. In 
Histocompatibility Testing 1984. E. D. Albert, M. P. Baur, and W. R. Mayr, editors. Springer-Verlag, Berlin. 667-755.

22. Tokunaga, K., K. Omoto, T. Fujii, and T. Juji. 1983. Haplotype study on HLA-linked genetic markers. Ishoku. 18:179-189.

23. Terasaki, P. I., and M. R. Mickey. 1975. HL-A haplotypes of 32 diseases. Transplant. Rev. 22:105-119.

24. Batchelor, J. R., J. Hors, I. A. Dodi, H. Betuel, and I. Borelli. 1984. Antigen report: HLA-DR2. In Histocompatibility Testing 1984. E. D. Albert, M. P. Baur, and W. R. Mayr, editors. Springer-Verlag, Berlin. 186-187.

25. Park, M. S., and P. I. Terasaki. 1980. Second DR locus. In Histocompatibility Testing 1980. P. I. Terasaki, editor. UCLA Tissue Typing Laboratory, Los Angeles. 578-582.

26. Ferrara, G. B., M. S. Park, N. Tanigaki, and P. I. Terasaki. 1984.
Antigen report: HLA-DQw1. In Histocompatibility Testing 1984. E. D. Albert, M. P. Baur, and W. R. Mayr, editors. Springer-Verlag, Berlin. 205-207.

27. Reinsmoen, N. L., T. Sasazuki, N. Kaneoka, N. Ohta, H. J. Noreen, L. J. Greenberg, and J. H. Kersey. 1978. Two distinct HLA-D specificities (DH0 and Dw2) in linkage with HLA-DRw2 as defined in white and Japanese populations. Transplant. Proc. 10:789-79i.

28. Spielman, R. S., J. Lee, W. F. Bodmer, J. G. Bodmer, and J. Trowsdale. 1984. Six HLA-D region $\alpha$-chain genes on human chromosome 6: polymorphisms and associations of DC $\alpha$-related sequences with DR types. Proc. Natl. Acad. Sci. USA. 81:3461-3465.

29. Choen, D., I. Le Gall, A. Marcadet, M. Font, J. Lalouel, and J. Dauseet. 1984. Clusters of HLA class II $\beta$ restriction fragments describe allelic series. Proc. Natl. Acad. Sci. USA. 81:7870-7874. 